\title{
Meteorological Variables and Suicidal Behavior: Air Pollution and Apparent Temperature Are Associated With High-Lethality Suicide Attempts and Male Gender
}

\begin{abstract}
Andrea Aguglia ${ }^{1,2 *}$, Gabriele Giacomini ${ }^{1,2}$, Elisa Montagna ${ }^{1,2}$, Andrea Amerio ${ }^{1,2,3}$, Andrea Escelsior ${ }^{1,2}$, Marco Capello ${ }^{4}$, Laura Cutroneo ${ }^{4}$, Gabriele Ferretti ${ }^{4}$, Davide Scafidi ${ }^{4}$, Alessandra Costanza ${ }^{5,6}$, Gianluca Serafini ${ }^{1,2}$ and Mario Amore ${ }^{1,2}$

${ }^{1}$ Section of Psychiatry, Department of Neuroscience, Rehabilitation, Ophthalmology, Genetics, Maternal, and Child Health, University of Genoa, Genoa, Italy, ${ }^{2}$ Istituto di Ricovero e Cura a Carattere Scientifico Ospedale Policlinico San Martino, Genoa, Italy, ${ }^{3}$ Department of Psychiatry, Tufts University, Boston, MA, United States, ${ }^{4}$ Department of Earth, Environment, and Life Sciences, University of Genoa, Genoa, Italy, ${ }^{5}$ Department of Psychiatry, Faculty of Medicine, University of Geneva (UNIGE), Geneva, Switzerland, ${ }^{6}$ Department of Psychiatry, Azienda Ospedaliera Nazionale Santi Antonio e Biagio e Cesare Arrigo Hospital, Alessandria, Italy
\end{abstract}

OPEN ACCESS

Edited by:

Domenico De Berardis,

Azienda UsI Teramo, Italy

Reviewed by:

Xenia Gonda,

Semmelweis University, Hungary

Marco Innamorati,

European University of Rome, Italy

*Correspondence:

Andrea Aguglia

andrea.aguglia@unige.it

Specialty section: This article was submitted to Mood and Anxiety Disorders, a section of the journal Frontiers in Psychiatry

Received: 14 January 2021 Accepted: 08 February 2021 Published: 05 March 2021

Citation: Aguglia A, Giacomini G, Montagna E, Amerio A, Escelsior A, Capello M, Cutroneo L, Ferretti G, Scafidi $D$, Costanza A, Serafini $G$ and Amore $M$ (2021) Meteorological Variables and

Suicidal Behavior: Air Pollution and Apparent Temperature Are Associated With High-Lethality Suicide Attempts and Male Gender

Front. Psychiatry 12:653390. doi: 10.3389/fpsyt.2021.653390
This study analyzed the impact of meteorological variables and high-lethality suicide attempts (HLSA) to assess a potential time shift of HLSA affected by climate evolution to predict the suicide attempt cases over different periods of the year. After attempting suicide, 225 subjects were admitted to the emergency ward of the IRCCS Ospedale Policlinico San Martino and later to the psychiatric unit from March 2016 to July 2018. Socio-demographic and clinical characteristics as well as the meteorological variables were collected. The Mann-Kendall test as well as redundancy and cross-correlation analyses were performed to analyze the trends, statistically correlations, and correspondence of the trends, respectively between suicidal behaviors and climatic factors. Sixty-seven (29.8\%) committed a HLSA. Our findings indicate a significant association between HLSA and male gender and apparent temperature with a strong correlation of $75 \%$ with a phase shift of -1 month. Solar radiation and air pollution $\left(\mathrm{PM}_{2.5}\right)$ have a positive correlation of 65 and $32 \%$, respectively, with a zero-time lag. Limitations include that the data are limited to a single hospital; psychological factors, or other clinical variables that could be ruled out as a trigger have not been considered. Meteorological variables may not mirror the temperature that the patient is exposed to due to the air conditioning systems. Exploring those environmental factors associated with HLSA in a more detailed manner could lead to early intervention and prevention strategies for such distressing admissions.

Keywords: suicide attempt, environmental parameters, apparent temperature, air pollution, hospitalization, suicide, suicidal behavior

\section{INTRODUCTION}

Suicide is a preventable public health issue causing more than 800.000 annual deaths globally; it is the second leading cause of death among 15- to 29-years-olds worldwide (1). 
Climate changes based on extreme temperatures, floods, drought, tornadoes, hurricanes, and wildfire can lead distress symptoms, suicidal behaviors, and psychiatric disorders in the general population. Global warming fits into this context with possible negative influence of environmental parameters on mental health and psychiatric disorders through both indirect and direct factors $(2,3)$. Changes in temperature, especially during the transition between winter and spring, can have remarkable consequences on suicidal behavior trends. Mental disorders and rates of attempted and complete suicidal behaviors have been studied for years to understand their trends and triggers and identify the influence of external risk factors such as social, economic, and environmental factors (4-6). In a multicenter study, a strong association was reported between climate effects vs. economic factors on suicidal behavior. The authors found that suicidality in Europe followed the climate/temperature change, which was from south to north-east (6). On the contrary, it has been hypothesized that higher lithium levels in drinking water may be associated with a reduced risk of suicidal behaviors in the general population (7-9).

Therefore, some research suggested that environmental conditions might be potentially important trigger factors. Specifically regarding meteorological variables, a positive correlation between seasonality (10-14) or sunlight exposure, also called photoperiod $(15,16)$, or latitude $(17)$, and suicidal behaviors has been shown. Recently, a significant association between hours of sunshine and violent completed suicides $(18,19)$ or high-lethality suicide attempts (HLSA) $(20,21)$ was reported. These findings were not confirmed by Veisani et al. (22) who showed seasonal trends in spring and autumn of suicides by violent methods and spring and summer for what concerns non-violent suicides.

The mechanisms underlying this association are still unclear and need further investigation. Therefore, other environmental variables such as increased ambient temperature or air pollution could be implicated in this complex phenomenon. A potential role of ambient or apparent temperature on suicidal behaviors has been studied with controversial results $(15,16,23-28)$. Several data, however, showed that a $26.6-60 \%$ of variation in suicidal behaviors could be explained by temperature fluctuations (29-31) but not with sunlight exposure, especially in completed suicide (16). Some researchers found a relationship between the warmest temperatures and suicide rates, mostly involving older subjects (32) and men relative to females (33) while others (34) found no association between weather variables and suicides in Colombia highlighting the absence of association in a tropical country where seasonal changes are not marked.

Among the environmental factors, air pollution and ozone could also have a detrimental impact on mental health. For example, Bernardini et al. (35) considered daily admissions to psychiatric emergency services in two Italian hospitals over a period of 2 years and highlighted that exposures to ozone may be associated with increased psychiatric admissions. Recently, several studies reported that higher levels of particulate matters $\left(\mathrm{PM}_{2.5}\right.$ and $\left.\mathrm{PM}_{10}\right)$ were linked to an increase in suicidal behaviors (attempts and deaths) worldwide (36-44), demonstrating both short- and long-term effects. Nevertheless, other studies report the absence of this association $(34,45)$. Although the specific mechanisms linking air pollution and suicide are uncertain, a growing body of research does suggest that the link is plausible.

Genoa has a population of about 600.000 inhabitants with an area of $240 \mathrm{~km}^{2}$. Its territory is located in the Liguria Region, and it has typically a Mediterranean climate with relatively temperate winters (mean temperature $8^{\circ} \mathrm{C}$ in January) and hot summers (mean temperature $24^{\circ} \mathrm{C}$ in July). Rains are concentrated in autumn (annual mean precipitation 1,100$1,300 \mathrm{~mm}$ ) (46). Genoa territory is ringed to the north by rugged mountains with wide gaps between them, which channel and control the movement of air masses. Therefore, despite the mild climate, these morphological characteristics combined with the fact that Genoa is located at the apex of the Ligurian sea on the northern side of one of the most active cyclogenetic areas in Europe, lead to frequent periods of unstable weather (47) that could affect the mental health of the population.

In recent decades, several climate changes have been reported in Genoa. For example, Faccini et al. (46) analyzed Genoa weather data between 1833 and 2014 and found that the annual mean temperature and rainfall rate (the ratio of annual rainfall and the number of rainy days) had a statistically positive trend $\left(+0.15^{\circ} \mathrm{C}\right.$ $\mathrm{yr}^{-1}$ and $+0.28 \mathrm{~mm} \mathrm{yr}^{-1}$, respectively) while rainy days had a negative trend $\left(-0.43 \mathrm{~d} \mathrm{yr}^{-1}\right)$ suggesting a shift toward more extreme weather.

Data from the Italian National Institute of Statistics (ISTAT; www.istat.it) suggested that the province of Genoa has attempted and completed suicide rates of 17.2 and 10.0 cases per 100.000 inhabitants, respectively. On the contrary, the city of Genoa had a mean of 23 cases per year of death by suicide from 2007-2017; the victims were mostly males (71\%).

To the best of our knowledge, no Italian study has yet reported data about meteorological parameters (including temperature and air pollution) and HLSA. Therefore, the aim of this study was to analyze the impact of several meteorological parameters such as air temperature, rain, solar radiation, and air pollutants, recorded by different measurement stations in Genoa (northwest Italy), on suicidal behaviors (especially HLSA). Second, we assessed a potential time shift of HLSA in a Mediterranean city characterized by a mild climate but affected by climate evolution such as the increase of flood events and temperature to predict the suicide attempt cases during the different periods of the year.

\section{MATERIALS AND METHODS}

\section{Sample}

We recruited individuals consecutively admitted for a suicide attempt (225 cases) and referred to the Emergency Department of IRCCS Ospedale Policlinico San Martino (Genoa) over a period of 2 years (from March 2016 to July 2018). This hospital works as for the whole Liguria region and the northwestern Italian area. It is the main hospital in Genoa and it is located in the eastern part of the city with a catchment area that extends to the neighboring municipalities. After clinical and medical evaluation, these individuals were admitted to the Psychiatric Unit. 
The inclusion criteria were: (a) being hospitalized in an emergency psychiatric ward for a suicide attempt; (b) age $>18$ years; and (c) the willingness to participate in the study by signing a written informed consent. The exclusion criteria were: (I) pregnancy or having just given birth; (II) having a positive history of acute neurological injuries such as neurodegenerative illnesses, intellectual disability, and loss of consciousness related to the presence of severe neurological conditions; (III) the assumption of melatonergic or lipid-lowering agents; (IV) the presence of acute or severe medical condition; and (V) the refusal or inability to provide a valid consent prior to participation in the study.

All participants received a detailed explanation of the study design and written informed consent was obtained from all respondents according to the guidelines provided in the current version of the Declaration of Helsinki. The study design was approved by the local Ethical Review Board.

\section{Assessment and Procedures}

Socio-demographic and clinical characteristics were investigated through the standardized clinical chart and lifetime computerized medical record used in our Psychiatric Unit. Age, gender, marital status, occupation, education level, suicide method, and psychiatric diagnosis according to the Diagnostic and Statistical Manual of Mental Disorders, fifth edition (DSM5) criteria (48) at discharge were recorded and grouped as in previous research $(49,50)$. All available information have been cross-referred and revised by two senior psychiatrists (MA and GS).

Silverman's operative definition of "suicide attempt" was used in the present study: a kind of suicide-related behavior classified as a suicidal act and characterized by self-inflicted, potentially injurious behavior with the non-fatal outcome for which there is evidence - either explicit or implicit - of the intent to die (51). Moreover, our definition involved the presence of a lethal intent that may be of varying intensity but needs to be present in the decision to carry out the suicidal act (52).

The cases of suicide attempts were divided into two subgroups based on the severity of the suicidal behaviors. The term "suicidal lethality" has not yet been defined comprehensively and, in our study, we adopted the concept of lethality as defined by Shneidman's (53) and Joiner's (54) criteria even used in recently published reports $(20,21,55,56)$. Methods of suicide attempt were dichotomized in terms of lethality. Therefore, a HLSA was defined as a suicide attempt that warranted hospitalization for at least $24 \mathrm{~h}$ and either treatment in a specialized unit (including intensive care unit, hyperbaric unit, or burn unit), surgery under general anesthesia, or extensive medical treatment (beyond gastric lavage, activated charcoal, or routine neurological observations), including antidotes for drug overdoses, telemetry, or repeated tests or investigations. Conversely, a low-lethality suicide attempt (LLSA) was defined as a suicide attempt that did not meet these criteria $(20,21,55,56)$.

The environmental parameters included air mean temperature $\left(\mathrm{T},{ }^{\circ} \mathrm{C}\right)$, precipitation $(\mathrm{P}, \mathrm{mm})$, wind speed (WS, $\left.\mathrm{m} \mathrm{sec}^{-1}\right)$, and relative humidity $(\mathrm{RH}, \%)$ data recorded by the Meteorological Observatory of the University of Genoa (MO$\mathrm{UNI})$. Solar radiation $\left(\mathrm{SR}, \mathrm{J} \mathrm{cm}^{-2}\right.$ ) and atmospheric pressure
(AP, $\mathrm{hPa}$ ) data were recorded by the weather station of the Regional Agency for the Protection of the Ligurian Environment (W-ARPAL). Particulate matter with diameter $\leq 10 \mu \mathrm{m}\left(\mathrm{PM}_{10}\right)$ and with diameter $\leq 2.5 \mu \mathrm{m}\left(\mathrm{PM}_{2.5} ; \mu \mathrm{g} \mathrm{m}^{-3}\right)$ as well as $\mathrm{CO}(\mathrm{mg}$ $\left.\mathrm{m}^{-3}\right), \mathrm{NO}_{2}\left(\mu \mathrm{g} \mathrm{m}^{-3}\right)$, and benzene $\left(\mu \mathrm{g} \mathrm{m}^{-3}\right)$ were measured via an air pollution detection station of ARPAL (P-ARPAL) (Genoa - Latitude: $44^{\circ} 24^{\prime} 40^{\prime \prime} \mathrm{N}$; Longitude: $008^{\circ} 55^{\prime} 58^{\prime \prime} \mathrm{E}$ ).

\section{Statistical Analysis}

Starting from data recorded by the weather station, the apparent temperature (AT) was calculated according to the following formula:

$$
A T=T+0.33 * W p-0.70 * W S-4.00
$$

where $T$ is the air temperature, $W S$ is the wind speed, and $W p$ is the water vapor pressure, calculated as following:

$$
W p=R H / 100 * 6.105 * \exp (17.27 * T /(237.7+T))
$$

where $R H$ is the relative humidity.

Distributions of monthly cases of attempted suicide and environmental parameters were statistically tested to find eventual significant trend: the Mann-Kendall trend test with a $p$ value $=0.05$, was applied by the statistical software ProUCL (v. 5.1; U.S. Environmental Protection Agency).

Redundancy analysis (RDA) (57) was applied to data on suicide attempts (HLSA, LLSA, and total cases). Environmental parameters (T, P, WS, RH, SR, AP, $\mathrm{PM}_{10}, \mathrm{PM}_{2.5}, \mathrm{CO}, \mathrm{NO}_{2}$, benzene) were used to find potential statistically correlations. RDA investigates the presence of relationships between the explanatory variables (meteorological parameters) and the response variables (the lethality of suicide attempts and gender) of a data matrix. Given the diversity between the ranges of the considered parameters, the data were standardized before the analysis. RDA was performed using the Brodgar software (Highland Statistics Ltd., v. 2.7.5, 2017).

The cross-correlation analysis was applied to the number of cases (total cases, HLSA, and LLSA) and to the environmental parameters that in the RDA showed a correlation with suicide attempts. The cross-correlation is a mathematical function that allows the comparison of two series by measuring the level of similarity and the time lag between them. To facilitate the interpretation of the cross-correlation function, the systems are normalized and ranges between -1 and +1 . If the value of the normalized cross-correlation is equal to 1 it means that the two series are identical (100\% positive correlation). If the series are not similar, then it tends to approach 0 . If a negative correlation is found, then they are anticorrelated and the value is $-1(100 \%$ negative correlation). The time to which the maximum value of the cross-correlation function represents the time lag between the two series. Cross-correlation was performed using PITSA software package (58). 


\section{RESULTS}

\section{Characterization of the Total Sample}

We included 225 subjects admitted for suicide attempt, of which $29.8 \%(N=67)$ presented a HLSA and $70.2 \%(N=$ $158)$ a LLSA. One hundred seventy five $(75.6 \%)$ were females, half of the individuals was unmarried, and about a third was actively working. Distributions of the different diagnoses did not show statistically significant trends, except for "other diagnoses", which decreased trend. The greatest number of cases are concentrated in the spring-summer months for bipolar disorder. The most commonly used method of suicide attempts was drug intoxication. Further details about sociodemographic and clinical characteristics are summarized in Table 1.

\section{Characteristics of Environmental Parameters}

All environmental parameters showed typical values and variations in the Mediterranean climate that characterizes the Genoa area. However, the beginning of 2018 was characterized by some peculiarities from the meteorological point of view: a relatively warmer January (mean temperature of $11.2^{\circ} \mathrm{C}$ in January 2018 compared to $7.5^{\circ} \mathrm{C}$ in January 2017), the shift of the minimum winter temperature in February, and a spring with high cumulative precipitation, especially in March 2018 $(178.8 \mathrm{~mm})$.

Distributions of all the environmental parameters analyzed are reported in Figure 1. Only temperature and solar radiation show a clear seasonality in the period typical of the mean latitude.

Among the environmental parameters, only $\mathrm{CO}, \mathrm{PM}_{10}$, and $\mathrm{PM}_{2.5}$ have statistically significant trends and all three have decreasing trends.

\section{Influence of Environmental Parameters}

Several tests with RDA, combining suicide lethality and gender (response variables) with the environmental parameters (explanatory variables), were made.

The Figure 2 shows the results of RDA carried out with HLSA, LLSA, gender, and environmental parameters. These results are obtained by using AT instead of the individual parameters WS, T, HP, and WP to better summarize the results. Furthermore, AT has been proven to characterize the physiological experience better than just the temperature or the other parameters alone [Niu et al. (27)]. In our case, SR, AT, and $\mathrm{PM}_{2.5}$ are very closely related to the HLSA and male subjects while LLSA and females are correlated to $\mathrm{NO}_{2}$ concentration and precipitation. Therefore, most findings demonstrate how SR and AT can influence the distribution of cases.

Following the RDA results, we applied cross-correlation analysis between pairs of parameters to verify the degree of relationship between an environmental parameter and one relating to suicide attempts and highlight the time lag between the two; hence, there is a delay in response in patients following the environmental stimulus.

Considering HLSA and AT (Figure 3), a positive and strong correlation of $75 \%$ was found with a phase shift of -1 month, i.e., suicide attempts peak with HLSA 1 month before reaching the
TABLE 1 | Sociodemographic and clinical characteristics of the total sample $(N=$ 225).

\begin{tabular}{|c|c|}
\hline Gender (female), $N(\%)$ & $170(75.6)$ \\
\hline \multicolumn{2}{|l|}{ Age, $N(\%)$} \\
\hline$<40$ years & $82(36.4)$ \\
\hline 40-60 years & $72(32.0)$ \\
\hline$>60$ years & $71(31.6)$ \\
\hline \multicolumn{2}{|l|}{ Education level, $N(\%):$} \\
\hline Primary school (1-5 years of school) & $9(4.0)$ \\
\hline Secondary school (6-8 years of school) & 66 (29.3) \\
\hline High school (9-13 years of school) & $112(49.8)$ \\
\hline Graduation and post (>14 years of school) & $38(16.9)$ \\
\hline \multicolumn{2}{|l|}{ Marital status, $N(\%)$} \\
\hline Unmarried & $109(48.4)$ \\
\hline Married & $43(19.1)$ \\
\hline Separated/divorced & $47(20.9)$ \\
\hline Widowed & $26(11.6)$ \\
\hline \multicolumn{2}{|l|}{ Working status, $N(\%)$} \\
\hline Unemployed & $150(66.7)$ \\
\hline Employed & 75 (33.3) \\
\hline \multicolumn{2}{|l|}{ Primary diagnosis, $N(\%)$ : } \\
\hline Bipolar and related disorders & $72(32.0)$ \\
\hline Schizophrenia and related disorders & $21(9.3)$ \\
\hline Depressive disorders & $72(32.0)$ \\
\hline Others & $60(26.7)$ \\
\hline \multicolumn{2}{|l|}{ Lethality of suicide attempt, $N(\%)$} \\
\hline High-lethality suicide attempt & $67(29.8)$ \\
\hline Low-lethality suicide-attempt & $158(70.2)$ \\
\hline \multicolumn{2}{|l|}{ Modality of suicide attempt, $N(\%)$} \\
\hline Drug intoxication & $147(65.3)$ \\
\hline Cuts & $35(15.6)$ \\
\hline Defenestration & $17(7.6)$ \\
\hline Weapon & $1(0.4)$ \\
\hline Stabbing & $3(1.3)$ \\
\hline Burn/gas/caustic & $14(6.2)$ \\
\hline Strangling & $8(3.6)$ \\
\hline
\end{tabular}

AT maximum in the phase of AT increase. Considering HLSA and solar radiation, a positive correlation of $65 \%$ is obtained with a zero-time lag: therefore, the monthly increase in solar radiation corresponds to a tight monthly increase in cases of HLSA and a decrease in light corresponds to a decrease in violent suicide attempts. Between HLSA and $\mathrm{PM}_{2.5}$, there is a $32 \%$ of correlation without time shift. Therefore, the increase in $\mathrm{PM}_{2.5}$ corresponds with an increase in suicide attempts albeit with a relatively low degree of correlation.

\section{DISCUSSION}

To our knowledge, this is the first Italian study investigating the correlation between HLSA and several meteorological variables. We found a significant association between three weather parameters (apparent temperature, solar radiation and $\mathrm{PM}_{2.5}$ ) 
A

B
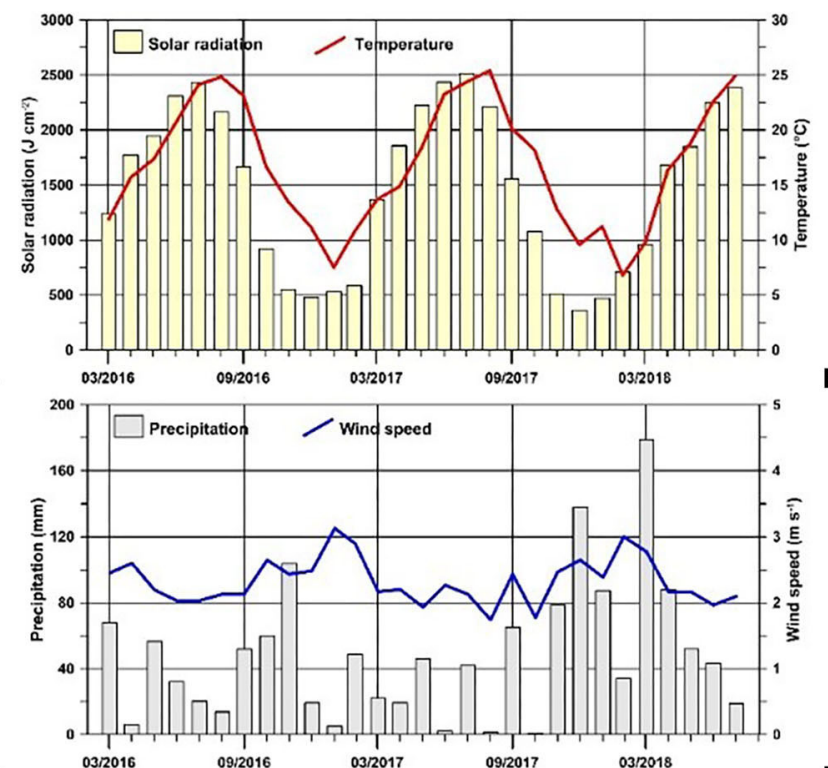

C

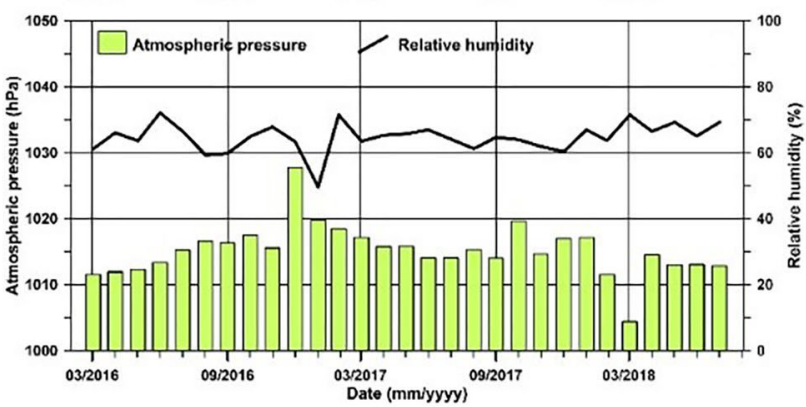

D

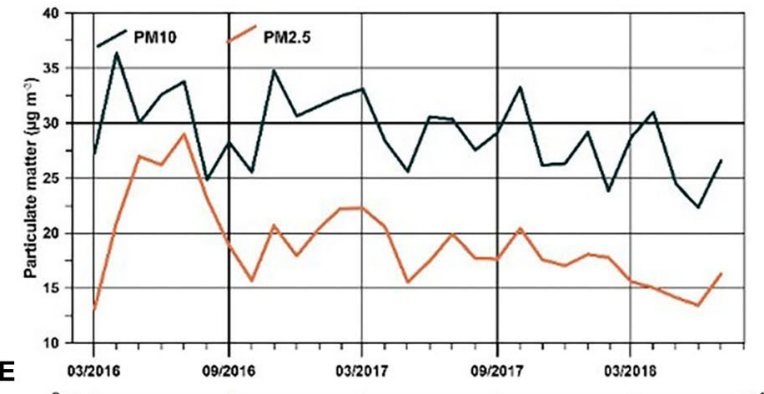

E

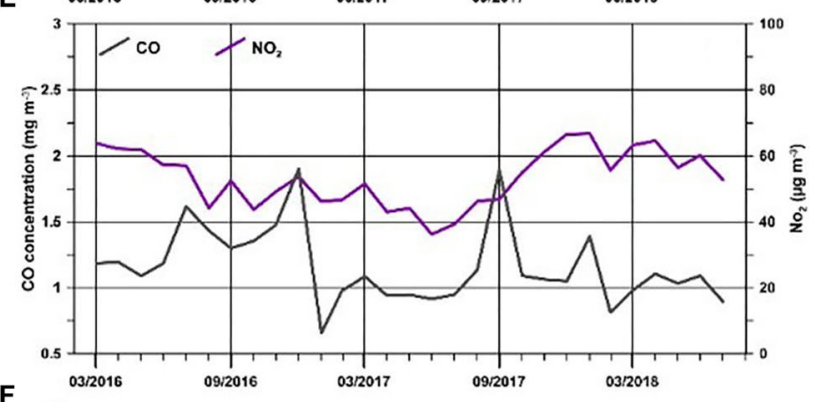

$\mathbf{F}$

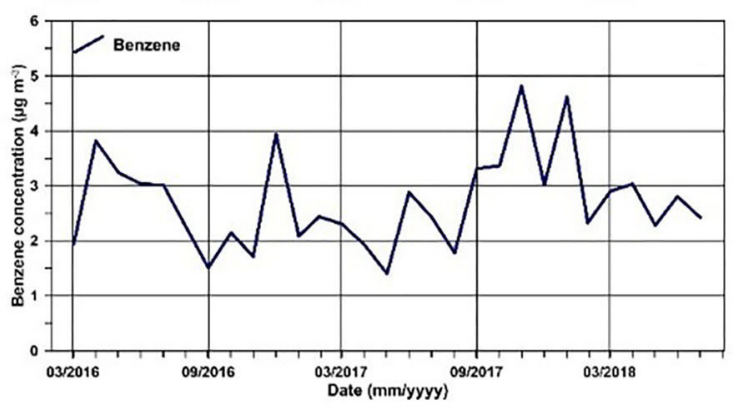

FIGURE 1 | Monthly distribution of (A) solar radiation (pale yellow bars) and temperature (red line); (B) precipitation (gray bars) and wind speed (blue line); (C) atmospheric pressure (green bars) and relative humidity (black line); (D) particulate matter concentrations ( $\mathrm{PM}_{10}$-dark green line and PM 2.5 -orange line); (E) $\mathrm{CO}$ (gray line) and $\mathrm{NO}_{2}$ (violet line) concentrations; (F) benzene concentrations (dark blue line).

and both HLSA and male gender. This is confirmed by Dumenčić et al. (33) that demonstrated, in a sample of 478 suicide attempts in Croatia over 10 years, a significant influence of temperature on males more than females.

It has been widely reported in literature that these variables influence not only the mental health but also suicidal behaviors. Nowadays, with global warming and a greater focus on climate issues, several efforts have been made in this direction. A recent meta-analysis (16) demonstrated a significant positive association between temperature rises and incidence of suicidal behaviors, while the potential role of solar radiation is more controversial (59), confirmed previously $(15,16,23-28,60,61)$. The innovative aspect of our study was the significant association of meteorological variables with HLSA.

As observed by Postolache et al. (62), several neurotransmitters (e.g., dopamine, norepinephrine, and serotonin) affect both mood and thermoregulation. Specifically, serotonin is a neurotransmitter regulating emotion that is sensitive to weather variability and light exposure, so springtime changes in expression might be associated with increased suicidal behavior $(63,64)$. Regarding biochemical mechanisms underlying this phenomenon, it has been proposed that warming temperatures enhance the responsiveness of $5-\mathrm{HT}_{2 \mathrm{~A}}$ receptors of the central nervous system (CNS) (65). The activation of $5-\mathrm{HT}_{2 \mathrm{~A}}$ receptors increases the sympathetic outflow to brown adipose tissue (BAT) (66) and hyperactivity of BAT impairs heat tolerance, and it could enhance the risk of suicidal behaviors. As proposed by Helama et al. (29): a potential association exists between psychiatric condition (i.e., anxiety and/or depressive symptomatology or disorders leading to suicidal behaviors) and altered transmission in the CNS projecting from BAT through the hypothalamus to the periaqueductal gray areas. Regarding structural brain findings, some authors have recently reported that individuals who commit HLSA could show larger pre-frontal cortex, caudate, and insula volumes compared to LLSA and individuals without suicidal behaviors. Furthermore, suicide attempters with familiarity for suicidal behavior reported smaller volumes in temporal regions, dorso-lateral pre-frontal 


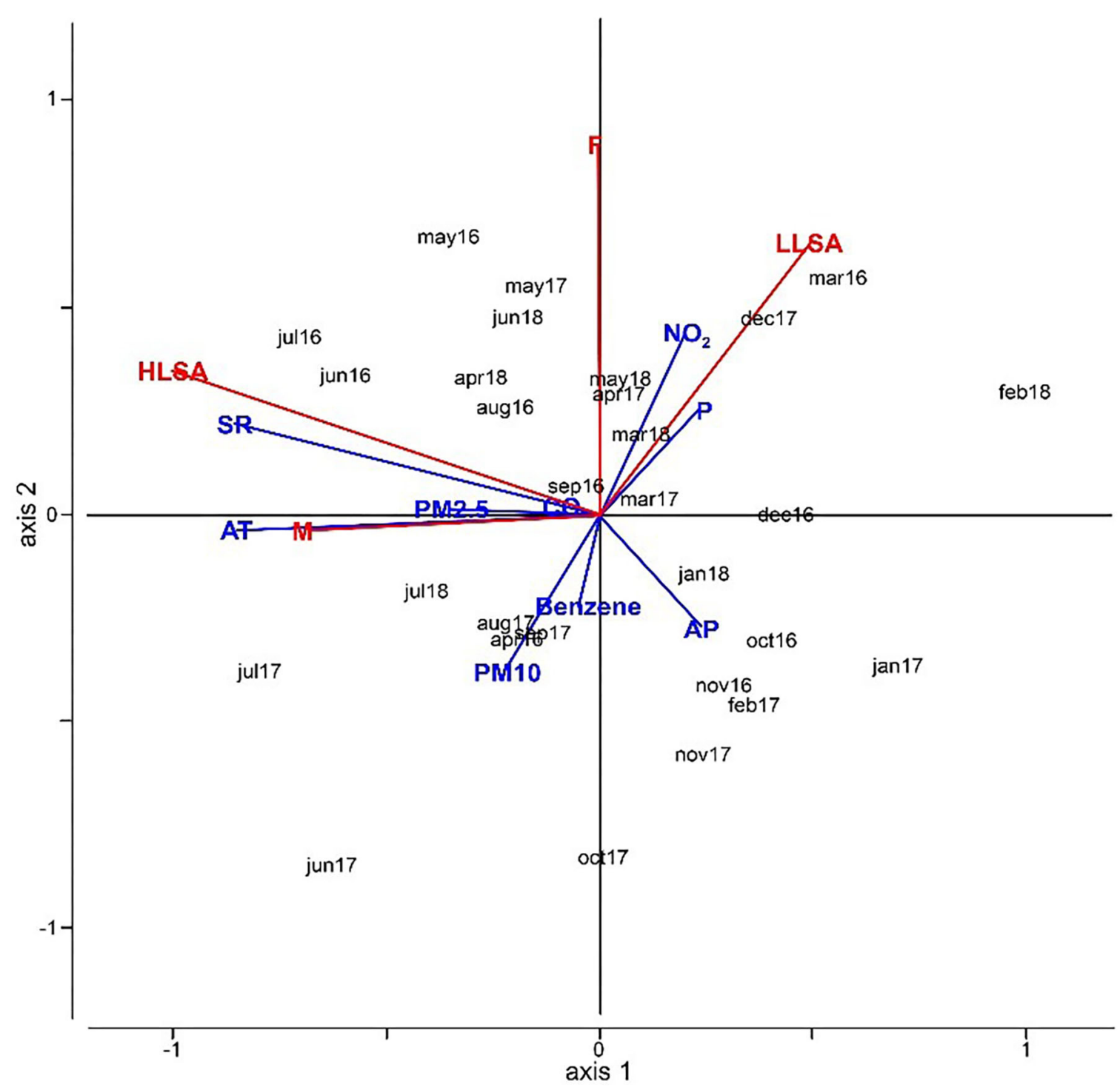

FIGURE 2 | RDA analysis combining suicide lethality and gender (response variables) with environmental parameters. The sum of all canonical eigenvalues is 0.42 .

cortex, and putamen. These cerebral structures play a role in cognitive process like decision making, inhibition, emotional dysregulation, and risk perception, and when compromised because of several factors (i.e., heat, climate change, sleepdeficiency), they could lead to more impulsive decisions and acts (67). Lastly, based on the assumption that similar areas of the insular cortex are activated during recall of feelings and sensation of pain and temperature (68), we assumed a link between the perception of significant heat and emotional correlation of discomfort, which could lead to suicidal behaviors in subjects at risk. Maes et al. (69) found a trend in L-tryptophan levels inversely related to the seasonal variation of violent suicides in the Belgian population. Furthermore, a correlation between peripheral dysfunctions of serotoninergic transmission, assessing metabolic, such as cholesterol and triglycerides, and hematologic, such as platelet-lymphocyte ratio and mean platelet volume, parameters and HLSA was demonstrated by recent findings $(55,56)$. A very recent review on the complex phenomenon of suicidal behaviors, conducted by Mann et al. (67) confirmed these findings and concluded that there is deficient serotonin release in HLSA. This is not likely due to serotonin biosynthesis, but seems to be associated with up-regulated serotonin $n_{1 A}$ $\left(5-\mathrm{HT}_{1 \mathrm{~A}}\right)$ auto-receptors located on serotonin neuron cell bodies and proximal dendrites (70) or postsynaptic cortical serotonin $2 \mathrm{~A}$ receptors $\left(5-\mathrm{HT}_{2 \mathrm{~A}}\right)$ that correlate with lifetime aggression severity (71). Serotonin dysfunction is more prominent in high-lethality suicidal behavior.

In our study, we found a positive correlation between HLSA and $\mathrm{PM}_{2.5}$. Recently, several studies confirmed our findings, reporting short- and long-term effects of higher levels of $\mathrm{PM}_{2.5}$ 

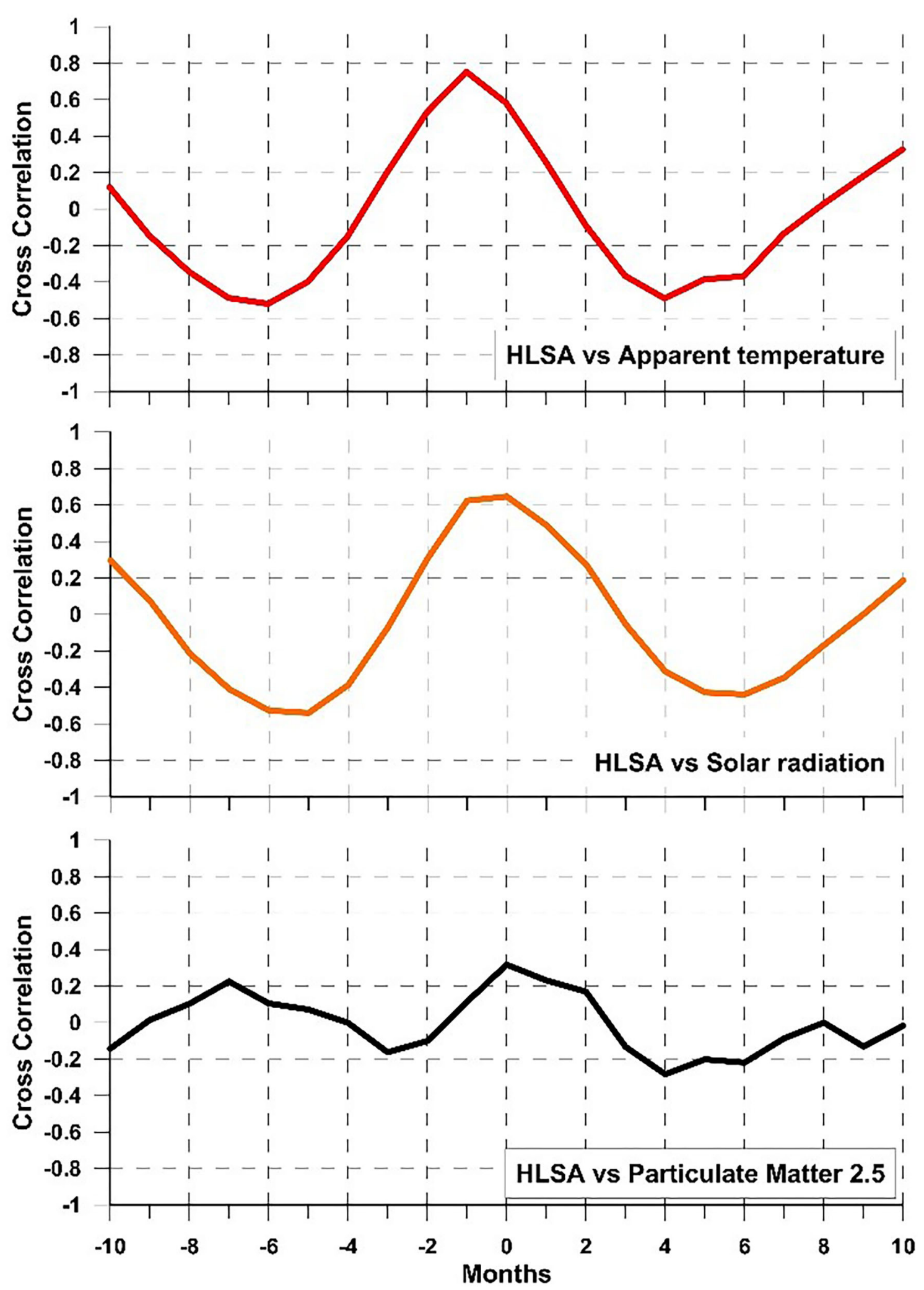

FIGURE 3 | Cross-correlation results: HLSA vs. apparent temperature (red); HLSA vs. solar radiation (orange); HLSA vs. PM 2.5 (black). 
and $\mathrm{PM}_{10}$ on suicidal behaviors, including attempted and completed suicides (36-44). However, the concentration and composition of air pollutants and population-level features (i.e., age and race) vary across countries.

The possible biological explanation of the observed association between air pollution and HLSA has not been clarified. A link between suicidal behaviors and inflammation was recently reported (6). Therefore, it is hypothesized that $\mathrm{PM}_{2.5}$ and $\mathrm{PM}_{10}$ could induce systematic inflammation/oxidative stress or impair hippocampal neurogenesis and neurotrophic factor expression, leading pollutants to play a causative role in the occurrence of psychological problems or suicide attempts. So, $\mathrm{PM}_{2.5}$ enters the olfactory bulb and reaches the basis nuclei (substantia nigra and striatum), causing a release of pro-inflammatory factors and cytokines, such as tumor necrosis factor-alpha (TNF- $\alpha$ ), interleukin-6 (IL-6) and interleukin-1beta (IL-1 $\beta$ ). Besides, air pollution causes a chronic activation of brain capillaries, astroglia, and, particularly, microglia, leading to inflammation and oxidative stress (72). Recently, Baharikhoob and Kolla (73) proposed the following relationship between microglial dysregulation and suicidal behaviors: proinflammatory cytokines (i.e., IL-1 $\beta$, TNF- $\alpha$, interferon-gamma (IFN- $\gamma$ ), and IL-6) would provoke neurotoxicity by increased glutamate (dependent on loss of inhibition in glutamatergic neurons). This hypothesis is confirmed by literature evidence, in which a significant correlation between higher IL-6 levels and suicide attempters' impulsivity was demonstrated (74). Furthermore, a recent study reported that high IL-6, IL-10, and C-reactive protein levels and activated microglia-related alterations were associated with greater suicidal ideation severity (75). Therefore, neuroinflammation seems to be one of the most involved factors in the pathogenesis of suicidal behavior and neurotoxicity and disrupted blood-brain barrier leads to impulsive, aggressive, and self-destructive behaviors.

Our study has several limitations. First, our data are limited to a single hospital. Second, psychological factors (e.g., life events, no compliance to treatment, and poor social support) that could be ruled out as triggers have not been considered. Furthermore, the effect of other clinical variables has not been investigated. Therefore, the generalization from our results should be made with caution. No structured interviews were performed to formulate psychiatric diagnoses and evaluate the lethality of suicide attempts (such as the Columbia Suicide Severity Rating scale). We preferred to rely upon Shneidman's and Joiner's definitions of lethality, although we acknowledge that using a specific instrument might provide adjunctive relevant data. Lastly, meteorological variables measured outdoor might not mirror the temperature the patient is exposed to, due to the increasing number of air conditioning systems. This might be responsible for the well-known ecological regression bias.

In conclusion, we found that apparent temperature, solar radiation and $\mathrm{PM}_{2.5}$ exposures were associated with an increased risk of HLSA in the Italian population. Our study extended prior results of an acute effect of seasonality and photoperiod on HLSA. Based on our findings, an increase in HLSA is expected within a month after a heatwave. Therefore, clinicians should monitor strictly high-risk subjects when hot temperatures occur and between the seasons (i.e., from spring to summer), playing a key role in predicting and preventing risky behaviors based on the knowledge of climatic variables. Furthermore, the correlation between multiple suicide attempters and climatic variables throughout the year is a crucial issue in the field of suicidology, assuming that a history of multiple attempters could be more vulnerable to heat stress. It is also necessary to evaluate the change in concentrations of air pollutants, as well as the degree of health damage, especially in areas of the world where air pollution is highest, and search potential biochemical mediators that could explain the greater influence of climatic and environmental factors in males than females.

Future prospective or cohort studies with a larger sample, exploring in a detailed manner these environmental factors, are warranted to further test the topic and clarify the impact of climatic factors on HLSA to reduce or prevent health damage, implementing early intervention for mental health promotion, especially focusing on vulnerable at-risk populations. Therefore, for suicidologists and their organizations, the potential rise in suicides is troubling and should lead to our support for those arguing for climate change policies. The organizations involved in suicide prevention should make public position statements, lending support to the growing demand for action on climate change (76).

\section{DATA AVAILABILITY STATEMENT}

The raw data supporting the conclusions of this article will be made available by the authors, without undue reservation, upon request.

\section{ETHICS STATEMENT}

The study was reviewed and approved by the Ethics Committee (IRCCS Ospedale Policlinico San Martino). The patients/participants provided their written informed consent to participate in this study.

\section{AUTHOR CONTRIBUTIONS}

AAg and LC designed the study and wrote the first draft of paper. $\mathrm{AE}$ and $\mathrm{AAm}$ participated to the first revision of original article and revised the English language. GG, AC, and EM collected the data and managed the literature searches. DS, LC, and GF undertook the statistical analyses and wrote the result section. GS, MA, and MC supervised the study design, search strategy reviewed, and edited the original draft. All Authors contributed to and approved the final version of the manuscript.

\section{ACKNOWLEDGMENTS}

This work was developed within the framework of the DINOGMI Department of Excellence of MIUR 2018-2022 (Law 232/2016). We thank the Ligurian Environmental Protection Agency for providing air pollution, solar radiation and atmospheric pressure data. 


\section{REFERENCES}

1. World Health Organization. Suicide Data. Available online at: https:// www.who.int/mental_health/prevention/suicide/suicideprevent/en (accessed 23 August, 2019).

2. Padhy SK, Sarkar S, Panigrahi M, Paul S. Mental health effects of climate change. Indian. J Occup Environ Med. (2015) 19:3-7. doi: 10.4103/0019-5278.156997

3. Cianconi $\mathrm{P}$, Betrò $\mathrm{S}$, Janiri L. The impact of climate change on mental health: a systematic descriptive review. Front Psychiatry. (2020) 11:74. doi: 10.3389/fpsyt.2020.00074

4. Fountoulakis KN, Savopoulos C, Zannis P, Apostolopoulou M, Fountoukidis I, Kakaletsis N, et al. Climate change but not unemployment explains the changing suicidality in Thessaloniki Greece (2000-2012). J Affect Disord. (2016) 193:331-8. doi: 10.1016/j.jad.2016.01.008

5. Bradvik L. Suicide risk and mental disorders. Int J Environ Res Public Health. (2018) 15:2028. doi: 10.3390/ijerph15092028

6. Serafini G, Parisi VM, Aguglia A, Amerio A, Sampogna G, Fiorillo A, et al. A specific inflammatory profile underlying suicide risk? Systematic review of the main literature findings. Int J Environ Res Public Health. (2020) 17:2393. doi: 10.3390/ijerph17072393

7. Pompili M, Vichi M, Dinelli E, Pycha R, Valera P, Albanese S, et al. Relationships of local lithium concentrations in drinking water to regional suicide rates in Italy. World J Biol Psychiatry. (2015) 16:567-74. doi: 10.3109/15622975.2015.1062551

8. Vita A, De Peri L, Sacchetti E. Lithium in drinking water and suicide prevention: a review of the evidence. Int Clin Psychopharmacol. (2015) 30:15. doi: 10.1097/YIC.0000000000000048

9. Palmer A, Cates ME, Gorman G. The association between lithium in drinking water and incidence of suicide across 15 Alabama counties. Crisis. (2019) 40:93-9. doi: 10.1027/0227-5910/a000535

10. Aguglia A, Moncalvo M, Solia F, Maina G. Involuntary admissions in Italy: the impact of seasonality. Int J Psychiatry Clin Pract. (2016) 20:2328. doi: 10.1080/13651501.2016.1214736

11. Galvão PVM, Silva HRSE, Silva CMFPD. Temporal distribution of suicide mortality: a systematic review. J Affect Disord. (2018) 228:13242. doi: 10.1016/j.jad.2017.12.008

12. Hofstra E, Elfeddali I, Bakker M, de Jong JJ, van Nieuwenhuizen C, van der Feltz-Cornelis CM. Springtime peaks and christmas troughs: a national longitudinal population-based study into suicide incidence time trends in the Netherlands. Front Psychiatry. (2018) 9:45. doi: 10.3389/fpsyt.2018. 00045

13. Rumble ME, Dickson D, McCall WV, Krystal AD, Case D, Rosenquist $\mathrm{PB}$, et al. The relationship of person-specific eveningness chronotype, greater seasonality, and less rhythmicity to suicidal behavior: a literature review. J Affect Disord. (2018) 227:721-30. doi: 10.1016/j.jad.2017. 11.078

14. Yu J, Yang D, Kim Y, Hashizume M, Gasparrini A, Armstrong B, et al. Seasonality of suicide: a multi-country multi-community observational study. Epidemiol Psychiatr Sci. (2020) 29:e163. doi: 10.1017/S2045796020000748

15. Dixon PG, Kalkstein AJ. Where are weather-suicide associations valid? An examination of nine US counties with varying seasonality. Int J Biometeorol. (2018) 62:685-97. doi: 10.1007/s00484-016-1265-1

16. Gao J, Cheng Q, Duan J, Xu Z, Bai L, Zhang Y, et al. Ambient temperature, sunlight duration, and suicide: a systematic review and metaanalysis. Sci Total Environ. (2019) 646:1021-9. doi: 10.1016/j.scitotenv.2018. 07.098

17. Björkstén KS, Kripke DF, Bjerregaard P. Accentuation of suicides but not homicides with rising latitudes of Greenland in the sunny months. BMC Psychiatry. (2009) 9:20. doi: 10.1186/1471-244X-9-20

18. Vyssoki B, Kapusta ND, Praschak-Rieder N, Dorffner G, Willeit M. Direct effect of sunshine on suicide. JAMA Psychiatry. (2014) 71:12317. doi: 10.1001/jamapsychiatry.2014.1198

19. Ludwig B, Dwivedi Y. The concept of violent suicide, its underlying trait and neurobiology: a critical perspective. Eur Neuropsychopharmacol. (2018) 28:243-51. doi: 10.1016/j.euroneuro.2017. 12.001
20. Aguglia A, Serafini G, Solano P, Giacomini G, Conigliaro C, Salvi $\mathrm{V}$, et al. The role of seasonality and photoperiod on the lethality of suicide attempts: a case-control study. J Affect Disord. (2019) 246:895901. doi: 10.1016/j.jad.2018.12.094

21. Aguglia A, Solano P, Parisi VM, Asaro P, Caprino M, Trabucco A, et al. Predictors of relapse in high lethality suicide attempters: a six-month prospective study. J Affect Disord. (2020) 271:32835. doi: 10.1016/j.jad.2020.04.006

22. Veisani Y, Delpisheh A, Sayehmiri K, Moradi G, Hassanzadeh J. Seasonality in violent and nonviolent methods of suicide attempts: a cross-sectional study on systematic registry data. Acta Med Iran. (2017) 55:507-13.

23. Bando DH, Teng CT, Volpe FM, de Masi E, Pereira LA, Braga AL. Suicide and meteorological factors in Sao Paulo, Brazil, 1996-2011: a time series analysis. Braz J Psychiatry. (2017) 39:220-7. doi: 10.1590/1516-4446-20 16-2057

24. Carleton TA. Crop-damaging temperatures increase suicide rates in India. Proc. Natl. Acad. Sci. USA. (2017) 114:8746-51. doi: 10.1073/pnas.170135 4114

25. Casas L, Cox B, Bauwelinck M, Nemery B, Deboosere P, Nawrot TS. Does air pollution trigger suicide? A case-crossover analysis of suicide deaths over the life span. Eur J Epidemiol. (2017) 32:973-81. doi: 10.1007/s10654-017-0273-8

26. Seregi B, Kapitany B, Maroti-Agots A, Rihmer Z, Gonda X, Dome P. Weak associations between the daily number of suicide cases and amount of daily sunlight. Prog Neuropsychopharmacol Biol Psychiatry. (2017) 73:418. doi: 10.1016/j.pnpbp.2016.10.003

27. Niu Y, Gao Y, Yang J, Qi L, Xue T, Guo M, et al. Short-term effect of apparent temperature on daily emergency visits for mental and behavioral disorders in Beijing, China: A time-series study. Sci Total Environ. (2020) 733:139040. doi: 10.1016/j.scitotenv.2020. 139040

28. Schneider A, Hampel R, Ladwig KH, Baumert J, Lukaschek K, Peters $A$, et al. Impact of meteorological parameters on suicide mortality rates: a case-crossover analysis in Southern Germany (1990-2006). Sci Total Environ. (2020) 707:136053. doi: 10.1016/j.scitotenv.2019. 136053

29. Helama S, Holopainen J, Partonen T. Temperature-associated suicide mortality: contrasting roles of climatic warming and the suicide prevention program in Finland. Environ Health Prev Med. (2013) 18:349-55. doi: 10.1007/s12199-013-0329-7

30. Ishii N, Terao T, Araki Y, Kohno K, Mizokami Y, Arasaki M, et al. Risk factors for suicide in Japan: a model of predicting suicide in 2008 by risk factors of 2007. J Affect Disord. (2013) 147:352-4. doi: 10.1016/j.jad.2012. 11.038

31. Fountoulakis KN, Chatzikosta I, Pastiadis K, Zanis P, Kawohl W, Kerkhof AJFM, et al. Relationship of suicide rates with climate and economic variables in Europe during 2000-2012. Ann Gen Psychiatry. (2016) 15:19. doi: 10.1186/s12991-016-0106-2

32. Chan EYY, Lam HCY, So SHW, Goggins WB III, Ho JY, Liu S, et al. Association between ambient temperatures and mental disorder hospitalizations in a subtropical city: a time-series study of Hong Kong special administrative region. Int J Environ Res Public Health. (2018) 15:754. doi: 10.3390/ijerph15040754

33. Dumenčić B, Rajc J, Marjanović K, PoŽgain I, Pavoković D. Impact of meteorological factors on suicide attempts and completed suicides in Croatia, Osijek-Baranja County. Psychiatr Danub. (2019) 31:40512. doi: $10.24869 /$ psyd.2019.405

34. Fernández-Niño JA, Flórez-García VA, Astudillo-García CI, RodríguezVillamizar LA. Weather and suicide: a decade analysis in the five largest capital cities of Colombia. Int J Environ Res Public Health. (2018) 15:1313. doi: 10.3390/ijerph15071313

35. Bernardini F, Attademo L, Trezzi R, Gobbicchi C, Balducci PM, Del Bello $\mathrm{V}$, et al. Air pollutants and daily number of admissions to psychiatric emergency services: evidence for detrimental mental health effects of ozone. Epidemiol Psychiatr Sci. (2019) 29:e66. doi: 10.1017/S20457960190 00623

36. Szyszkowicz M, Willey JB, Grafstein E, Rowe BH, Colman I. Air pollution and emergency department visits for suicide attempts in Vancouver, 
Canada. Environ Health Insights. (2010) 4:79-86. doi: 10.4137/EHI. S5662

37. Bakian AV, Huber RS, Coon H, Gray D, Wilson P, McMahon WM, et al. Acute air pollution exposure and risk of suicide completion. Am J Epidemiol. (2015) 181:295-303. doi: 10.1093/aje/kwu341

38. Kim Y, Myung W, Won HH, Shim S, Jeon HJ, Choi J, et al. Association between air pollution and suicide in South Korea: a nationwide study. PLoS ONE. (2015) 10:e0117929. doi: 10.1371/journal.pone.01 17929

39. Ng CF, Stickley A, Konishi S, Watanabe C. Ambient air pollution and suicide in Tokyo, 2001-2011. J Affect Disord. (2016) 201:194202. doi: 10.1016/j.jad.2016.05.006

40. Kim Y, Ng CFS, Chung Y, Kim H, Honda Y, Guo YL, et al. Air pollution and suicide in 10 cities in northeast asia: a time-stratified case-crossover analysis. Environ. Health. Perspect. (2018) 126:037002. doi: 10.1289/EHP2223

41. Lee H, Myung W, Kim SE, Kim DK, Kim H. Ambient air pollution and completed suicide in 26 South Korean cities: effect modification by sociodemographic and socioeconomic factors. Sci Total Environ. (2018) 639:944-51. doi: 10.1016/j.scitotenv.2018. 05.210

42. Min JY, Kim HJ, Min KB. Long-term exposure to air pollution and the risk of suicide death: a population-based cohort study. Sci Total Environ. (2018) 628-9:573-9. doi: 10.1016/j.scitotenv.2018. 02.011

43. Chen Y, He G, Chen B, Wang S, Ju G, Ge T. The association between $\mathrm{PM}_{2.5}$ exposure and suicidal ideation: a prefectural panel study. BMC Public Health. (2020) 20:293. doi: 10.1186/s12889-02 0-8409-2

44. Luo Z, Hou Y, Chen G, Wang F, Tu R, Dong X, et al. Long-term effects of ambient air pollutants on suicidal ideation in China: the henan rural cohort study. Environ Res. (2020) 188:109755. doi: 10.1016/j.envres.2020.109755

45. Santurtún M, Sanchez-Lorenzo A, del Real Á, Zarrabeitia MT, Santurtún A. Association between suicide and environmental variables in the North of Spain: a 14-year analysis. Cult Med Psychiatry. (2018) 42:64753. doi: 10.1007/s11013-018-9578-7

46. Faccini F, Luino F, Sacchini A, Turconi L, De Graff JV. Geohydrological hazards and urban development in the Mediterranean area: an example from Genoa (Liguria, Italy). Nat Hazards Earth Syst. (2015) 15:263152. doi: 10.5194/nhess-15-2631-2015

47. Capello M, Cutroneo L, Ferretti G, Gallino S, Canepa G. Changes in the physical characteristics of the water column at the mouth of a torrent during an extreme rainfall event. J Hydrol. (2016) 541:14657. doi: 10.1016/j.jhydrol.2015.12.009

48. American Psychiatric Association. Diagnostic and Statistical Manual of Mental Disorders. 5th ed. Arlington VA: American Psychiatric Publishing (2013). doi: 10.1176/appi.books.9780890425596

49. Aguglia A, Borsotti A, Cuniberti F, Serafini G, Amore M, Maina G. The influence of sunlight exposure on hospitalization in emergency psychiatry. Chronobiol Int. (2017) 34:1413-22. doi: 10.1080/07420528.2017.1374286

50. Aguglia A, Borsotti A, Maina G. Bipolar disorders: is there an influence of seasonality or photoperiod? Braz J Psychiatry. (2018) 40:6-11. doi: 10.1590/1516-4446-2016-2144

51. Silverman MM, Berman AL, Sanddal ND, O'Carroll PW, Joiner TE. Rebuilding the tower of Babel: a revised nomenclature for the study of suicide and suicidal behaviors. Part 1: background, rationale, and methodology. Suicide Life Threat Behav. (2007) 37:248-63. doi: 10.1521/suli.2007.37.3.248

52. Pompili M, Goracci A, Giordano G, Erbuto D, Girardi P, Klonsky ED, et al. Relationship of non-suicidal self-injury and suicide attempt: a psychopathological perspective. J Psychopathol. (2015) 21:348-53.

53. Shneidman ES. The Suicidal Mind. NewYork, NY: Oxford University Press (1996). p. 133.

54. Joiner T. Why People Die by Suicide. Cambridge, MA: Harvard University Press (2007). p. 37. doi: 10.2307/j.ctvjghv2f

55. Aguglia A, Solano P, Giacomini G, Caprino M, Conigliaro C, Romano M, et al. The association between dyslipidemia and lethality of suicide attempts: a case-control study. Front Psychiatry. (2019) 10:70. doi: 10.3389/fpsyt.2019. 00070
56. Aguglia A, Amerio A, Asaro P, Caprino M, Conigliaro C, Giacomini G, et al. High-lethality of suicide attempts associated with platelet to lymphocyte ratio and mean platelet volume in psychiatric inpatient setting, World J Biol Psychiatry. (2020). doi: 10.1080/15622975.2020.17 61033. [Epub ahead of print].

57. Zuur AF, Ieno EN, Smith GM. Analysing Ecological Data. New York, NY: Springer (2007). doi: 10.1007/978-0-387-45972-1

58. Scherbaum F, Johnson J. PITSA, Programmable Interactive Toolbox for Seismological Analysis. Munich: University of Munich (1993).

59. Jee HJ, Cho CH, Lee YJ, Choi N, An H, Lee HJ. Solar radiation increases suicide rate after adjusting for other climate factors in South Korea. Acta Psychiatr Scand. (2019) 135:219-27. doi: 10.1111/acps.12676

60. Parks RM, Bennett JE, Tamura-Wicks H, Kontis V, Toumi R, Danaei $\mathrm{G}$, et al. Anomalously warm temperatures are associated with increased injury deaths. Nat Med. (2020) 26:65-70. doi: 10.1038/s41591-01 9-0721-y

61. Yarza S, Vodonos A, Hassan L, Shalev H, Novack V, Novack L. Suicide behavior and meteorological characteristics in hot and arid climate. Environ Res. (2020) 184:109314. doi: 10.1016/j.envres.2020. 109314

62. Postolache TT, Mortensens PB, Tonelli LH, Jiao X, Frangakis C, Soriano JJ, et al. Seasonal prong peaks of suicide victims with and without prior history of mood disorders. J Affect Disord. (2010) 121:88-93. doi: 10.1016/j.jad.2009.05.015

63. Lambert GW, Reid C, Kaye DM, Jennings GL, Esler MD. Effect of sunlight and season on serotonin turnover in the brain. Lancet. (2002) 360:18402. doi: 10.1016/S0140-6736(02)11737-5

64. Praschak-Rieder N, Willeit $M$, Wilson AA, Houle S, Meyer JH. Seasonal variation in human brain serotonin transporter binding. Arch Gen Psychiatry. (2008) 65:1072-8. doi: 10.1001/archpsyc.65. 9.1072

65. Zhang G, Tao R. Enhanced responsivity of 5-HT(2A) receptors at warm ambient temperatures is responsible for the augmentation of the 1-(2,5dimethoxy-4-iodophenyl)-2-aminopropane (DOI)-induced hyperthermia. Neurosci Lett. (2011) 490:68-71. doi: 10.1016/j.neulet.2010.12.028

66. Ootsuka Y, Blessing WW. Thermogenesis in brown adipose tissue: increase by 5-HT2A receptor activation and decrease by 5HT1A receptor activation in conscious rats. Neurosci. Lett. (2006) 395:170-4. doi: 10.1016/j.neulet.2005.10.062

67. Mann JJ, Rizk MM. A brain-centric model of suicidal behavior. Am J Psychiatry. (2020) 177:902-16. doi: 10.1176/appi.ajp.2020.20081224

68. Kandel ER, Schwartz JH, Jessell TM, Siegelbaum SA, Hudspeth AJ. Principles of Neural Science. 5th ed. Mc Graw Hill Medical (2013).

69. Maes M, Scharpé S, Verkerk R, D’Hondt P, Peeters D, Cosyns P, et al. Seasonal variation in plasma L-tryptophan availability in healthy volunteers. Arch Gen Psychiatry. (1995) 52:937-46. doi: 10.1001/archpsyc.1995.03950230051008

70. Sullivan GM, Oquendo MA, Milak M, Miller JM, Burke A, Ogden RT, et al. Positron emission tomography quantification of serotonin $(1 \mathrm{~A})$ receptor binding in suicide attempters with major depressive disorder. JAMA Psychiatry. (2015) 72:169-78. doi: 10.1001/jamapsychiatry.2014.2406

71. Oquendo MA, Russo SA, Underwood MD, Kassir SA, Ellis SP, Mann JJ, et al. Higher postmortem prefrontal 5-HT2A receptor binding correlates with lifetime aggression in suicide. Biol Psychiatry. (2006) 59:23543. doi: 10.1016/j.biopsych.2005.06.037

72. Block ML, Calderón-Garcidueñas L. Air pollution: mechanism of neuroinflammation \& CNS disease. Trends Neurosci. (2009) 32:506-16. doi: 10.1016/j.tins.2009.05.009

73. Baharikhoob P, Kolla NJ. Microglial dysregulation and suicidality: a stressdiathesis perspective. Front Psychiatry. (2020) 11:781. doi: 10.3389/fpsyt.2020. 00781

74. Isung J, Aeinehband S, Mobarrez F, Nordstrom P, Runeson B, Asberg $M$, et al. High interleukin-6 and impulsivity: determining the role of endophenotypes in attempted suicide. Transl Psychiatry. (2014) 4:e470. doi: 10.1038/tp.2014.113

75. Suzuki H, Ohgidani M, Kuwano N, Chretien F, de la Grandmaison GL, Onaya $\mathrm{M}$, et al. Suicide and microglia: recent findings and future perspectives based on human studies. Front Cell Neurosci. (2019) 13:31. doi: $10.3389 /$ fncel.2019.00031 
76. Lester D. The environment and suicide - why suicidologists should support climate change policies. Crisis. (2021). doi: 10.1027/0227-5910/a000752. [Epub ahead of print].

Conflict of Interest: The authors declare that the research was conducted in the absence of any commercial or financial relationships that could be construed as a potential conflict of interest.
Copyright (c) 2021 Aguglia, Giacomini, Montagna, Amerio, Escelsior, Capello, Cutroneo, Ferretti, Scafidi, Costanza, Serafini and Amore. This is an open-access article distributed under the terms of the Creative Commons Attribution License (CC $B Y)$. The use, distribution or reproduction in other forums is permitted, provided the original author(s) and the copyright owner(s) are credited and that the original publication in this journal is cited, in accordance with accepted academic practice. No use, distribution or reproduction is permitted which does not comply with these terms. 